Evidence Based Practice: What is it? and Why Does it Matter?

\section{Vanora Hundley}

The terms 'evidence' and 'evidence-based practice' are now common place in health care literature. Government reports make increasing use of these terms and seek to encourage all health professionals to base their practice on sound evidence (Department of Health (DOH) 1996, 1997, 1998; Scottish Office, 1997, 1998, 1998b). So what exactly is 'evidence based practice' and where did the term come from

\section{What is evidence?}

Health professionals including chaplains, acquire their knowledge from a number of sources. These include:

- Tradition - !t has always been done that way (handing down of experience)

- Authority/policy - 1 was told to do it that way (this can be through written authority such as policies or guidelines or from people in authority such as a manager)

- Education or training - 1 was taught to do it that way

- Personal experience - 1 have found it usually works

- Trial and error - 1 have tried several ways and this one seems to work best

- Role modelling - 1 have seen others do it this way

- Intuition - It feels right this way

- Research - The research I have read suggests this is the best method

(adapted from Rees, 1997)

Knowledge gained from any of these sources may lack a sound basis. However, some sources of knowledge are less reliable than others. In particular, tradition is considered to be a poor basis for practice because many such practices when evaluated have been shown to be of little benefit and may in fact cause discomfort or harm (Walsh and Ford, 1989). The routine shaving of women in labour (Romney, 1980) and the routine use of enemas during labour (Romney and Gordon, 1981) are well known examples of traditional midwifery practices which were found to be harmful to women.

Role modelling can be a very influential way of learning. However, as Antman and colleagues (1992) found expert opinion, whether written or in the clinical setting, is not always up to date. Antman et al (1992) reviewed the evidence about treatments for myocardial infarction and found that despite considerable research evidence showing the effectiveness of a number of treatments the majority of experts did not recommend them. In particular, they describe how clinicians ignored important evidence regarding thrombolytic therapy thereby delaying its introduction into clinical practice. The first study to demonstrate the effectiveness of thrombolytic drugs in reducing mortality following myocardial infarction reported in the early 1970's. Yet more than 13 years passed before even half the experts recommended using this as a method of treatment. Nor was evidence from a metaanalysis sufficient to change practice. The first metaanalysis, reported in 1985, showed that thrombolytic therapy significantly reduced the risk of death following myocardial infarction by approximately $20 \%$. It was to be a further 6 years before the majority of experts recommended its use. Readers are referred to Keeble and Clarke (1995) for a more detailed discussion of the problems associated with each source of knowledge. It is clear that health professionals need reliable sources of knowledge. These reliable sources of knowledge are often referred to as 'evidence' and their use as 'evidence based decision making' or 'evidence based practice.'

\section{What is evidence based practice?}

Evidence based practice has been described as: "the conscientious, explicit and judicious use of current best evidence when making decisions about individual patients." (Muir Gray, 1997)

This definition indicates that evidence based practice involves more than just 'using' the evidence. There is a need for balance between the use of evidence and clinical expertise. We have seen that without a sound basis, practice may be ineffective or worse, harmful to the patient. Having found a source of evidence, the health professional must use their skills, including those of critical appraisal, to assess the evidence in terms of its quality and applicability. However, even if the evidence is found to be of a high quality this is not sufficient on its own. The health professional must also decide whether the evidence is appropriate for this particular patient in these particular circumstances (Sackett et al, 1996). If evidence is simply applied 'cookbook' fashion without clinical expertise then there is a risk that the care may be neither appropriate nor applicable for the individual patient. Therefore, evidence based practice should involve evidence, clinical expertise and the preferences of the patient/client in planning the individual patient's care. 


\section{Where did it come from?}

The use of research as a sound basis for health care practice is not new (Cochrane 1972, Department of Health and Social Security, 1972) but pressure to ensure that practice is research based has increased considerably in the last decade (DOH 1991, 1993). Evidence based practice originated in the field of medicine as a means of improving the quality of decision-making using clinical research (EvidenceBased Medicine Working Group, 1992). However, other multidisciplinary groups, such as the Cochrane Collaboration, were also examining ways of increasing the availability of sound research evidence and the publication of a number of systematic reviews in 'Effective care in pregnancy and childbirth' (Chalmers et al, 1989) led the way in making research more accessible.

What evidence is appropriate in which circumstances?

There has been considerable debate about what constitutes 'best evidence' for practice (Iggo, 1995; Walsh, 1996; French 1999). The origins of evidence based practice have meant that there has been a tendency to see 'evidence' in terms of quantitative research such as randomised controlled trials and systematic reviews. However, the type of evidence used will depend on the clinical situation, the question to be answered and the type of decision being made. Questions about clinical effectiveness are best answered by research where this is available and ideally by research that can determine cause and effect. Here it is important to eliminate other possible causes or factors and therefore the preferred type of study is a randomised controlled trial. Nonrandomised studies can lead to false positive conclusions about effectiveness. However, for many effects or outcomes one single randomised controlled trial will not be large enough to determine whether the cause makes a real difference. Therefore, it is best to use a systematic review of a number of trials where a good quality review exists.

Unfortunately, research simply isn't available to answer many questions about clinical effectiveness and it has been estimated that as few as 15$20 \%$ of medical interventions have been scientifically demonstrated to be effective (Kings Fund Annual Report, 1993; Freemantle N, 1995). As a result, consensus opinion is probably still the most commonly used method. Consensus opinion is ascertained from surveys of professionals' knowledge, attitudes and practices (Penney et al., 1994) and may also involve surveys of service users. However, it is worth remembering that consensus and expert opinion often lag behind and are frequently inconsistent with the evidence (Antman et al., 1992). If there is neither research

evidence nor consensus opinion in an area of care, then the practitioner must use their own knowledge in deciding good practice. Thus, there are different levels of evidence when considering clinical effectiveness with a good quality systematic review being the best evidence. Various systems exist for weighting or grading the other types of evidence. One of the simplest is the one used by the NHS executive for classifying evidence to be used in clinical guidelines (Mann, 1996). Three categories are used with category A being the preferred option. The categories are:

A. randomised controlled trials

B. other robust experimental or observational studies

C. more limited evidence but the advice relies on expert opinion and has the endorsement of respected authorities

Where decisions are made on the basis of $\mathrm{C}$ rated evidence, the health professional must acknowledge the limitations in comparison to using research evidence. This should be discussed openly with the patient/client.

Although the focus has been on using evidence to answer questions about clinical effectiveness, clinicians are now looking at applying evidence to other areas of practice. Walsh (1996) describes how they used both quantitative and qualitative research to draw up evidence-based guidelines for the care of women in labour (The Leicester Royal Infirmary NHS Trust, 1996). Evidence for issues of clinical effectiveness was drawn from the Cochrane Database where available and therefore involved systematic reviews of randomised controlled trials. Areas such as communication were informed through ethnographic studies and a study employing grounded theory provided insights into the inclusion of partners in the women's care.

Other health professionals have used qualitative research methods to highlight patients' experiences and plan appropriate services. Davis et al. (1996) interviewed patients with terminal illness and their carers to determine the areas of service provision that were lacking and make appropriate changes. In another study, patients' experiences of a practice nurse-led service were used to identify areas for practice nurse training to enable a high quality service to be developed (Wiles, 1997).

Qualitative research can also be a valuable source of evidence in understanding patients' 
experiences. Smith (1998) used phenomenology to describe and understand the problem drinker's lived experience of suffering. The findings, he suggests, have important implications for those working with problem drinkers. Some questions, such as those relating to moral and ethical issues, cannot be answered by research. Such questions may arise in areas such as surrogacy, organ donation, and euthanasia. In these cases evidence is usually determined by consensus or expert opinion.

\section{Why does it matter?}

It is clear from the work by Amman et al (1992) that clinicians' ignorance of existing evidence of effective drug treatment for myocardial infarction resulted in unnecessary mortality and morbidity. Other drugs given without a full understanding of the potential side effects can be equally disastrous as demonstrated in the 1960's with the use of thalidomide in pregnancy. Few of us would argue with the fact that if we needed to visit the doctor we would want him or her to use the best evidence available in planning our treatment. But if you aren't involved in prescribing medicines or delivering interventions does it really matter?

Recent reports have highlighted the need for evidence based patient information to avoid the mismatch that often occurs between clinicians' beliefs about the information needs of patients and the patients' actual needs (Entwistle et al., 1996; Coulter, 1998). A study by Meredith et al. (1995) highlights this disparity. The study looked at the experiences of men who had undergone prostate surgery and examined the information that surgeons routinely gave to their patients. They found that many topics of relevance to patients, such as negative side effects of surgery, were omitted in printed information sheets. In addition, patients reported that their experience of the surgery and the after effects had differed considerably from that described by their surgeons. In the same way, health professionals who provide support and counselling to patients/clients can benefit from using evidence. There has been a tendency to assume that the professional knows best. By using evidence such as the lived experience described in phenomenological research, the health professional can develop a greater understanding of how the patient/client experiences their condition.

\section{Conclusion}

This paper has given a very brief overview of the terms evidence and evidence-based practice. It is hoped that this will stimulate debate about the subject. Although evidence-based medicine has been around for a number of years, the use of evidence in other areas of practice is still developing. Health professionals should use the opportunity to explore what sources of evidence are appropriate to their area of practice and how they can be used to improve the care of patients/clients.

\section{References}

Amman E.M., Lao J., Kupelnick B., Mosteller F., Chalmers T. C. (1992) A comparison of results of meta-analyses of randomized controlled trials and recommendations of clinical experts: treatments for myocardial infarction. JAMA 268: 240-248.

Chalmers I, Enkin M, Keirse MJNC. (1989) Effective Care in Pregnancy and Childbirth. (Vol. I and II) Oxford University Press, Oxford.

Cochrane AL. (1972) Effectiveness and Efficiency. Random Reflections on Health Services. London: Nuffield Provincial Hospitals Trust.

Coulter A. (1998) Evidence based patient information. British Medical Journal. 317: 225226.

Davis BD, Cowley SA and Ryland RK. (1996) The effect of terminal illness on patients and their carers. Journal of Advanced Nursing. 23: 512520.

Department of Health and Social Security (1972) Report of the Committee on Nursing (Briggs Report). HMSO, London.

Department of Health. (1991) Research for Health: A Research and Development Strategy for the NHS, HMSO, London.

Department of Health. (1993) Strategy for Research in Nursing, Midwifery and Health Visiting, HMSO, London.

Department of Health (1996) Research and Development. Towards an evidence-based health service. HMSO, London.

Department of Health (1997) The New NHS: Modern, Dependable. HMSO, London. Department of Health (1998) A First Class Service: Quality in the new NHS. HMSO, London. Entwistle V, Watt IS, and Herring JE. (1996) Information about Health Care Effectiveness: An introduction for consumer health information providers. King's Fund, London. EvidenceBased Medicine Working Group (1992)

Evidence-Based Medicine: a new approach to teaching the practice of medicine. JAMA 268: 2420-2425.

Freemantle N (1995) Dealing with uncertainty: will science solve the problem of resource allocation in the UK NHS? Social Science in Medicine. 40 (10): 1365-70. 
French P (1999) The development of evidencebased nursing. Journal ofAdvanced Nursing. 29 (1): $72-78$.

Iggo N (1995) Evidence-based Medicine (letter) The Lancet. 346: 839.

Keeble S. and Clarke E. (1995) Sources of Nursing and Midwifery Knowledge. Research Awareness Module 2. Distance Learning Centre, South Bank University, London.

Kings Fund Annual Report (1993). Strengthening the knowledge-base of clinical practice. King Edward's Hospital Fund, London. 13

The Leicester Royal Infirmary NHS Trust (1996) Evidence-Based Guidelines Intrapartum Midwife-Led Care for Midwives. Obstetrics \& Gynaecology Directorate, Leicester Royal Infirmary. Leicester.

Mann T. (1996) Clinical Guidelines: Using clinical guidelines to improve patient care within the NHS. NHS Executive, Leeds.

Meredith P, Emberton M, Wood C and Smith J. (1995) Comparison of patients' needs for information on prostate surgery with printed materials provided by surgeons. Quality in Health Care 4: 18-23.

Muir Gray J.A. (1997) Evidence-based Healthcare. How to make health policy and management decisions. Churchill Livingstone, London. Page 213

Penney G. C., Glasier A., and Templeton A. (1994) A multi-centre, criterion based audit of the management of induced abortion in Scotland. British Medical Journal 309: 15-18.

Rees C. (1997) An Introduction to Research for Midwives. Chapter 1 - Why research? $\mathrm{p}$ 1-7. Books for Midwives Press, Cheshire.

Romney M. (1980) Predelivery shaving: an unjustified assault? Journal of Obstetrics and Gynaecology. 1:33-35.
Romney M. and Gordon H. (1981) Is your enema really necessary? British Medical Journal. 282: 1269-1271

Sackett D.L., Rosenberg W.M., Muir Gray J.A., Haynes R.B., Richardson W.S. (1996) Evidence based medicine: what it is and what it isn't. British Medical Journal. 312: 71-72. Scottish Office, Department of Health (1997) Designed to Care: renewing the National Health Service in Scotland. The Stationary Office, Edinburgh.

Scottish Office, Department of Health (1998) Clinical Governance: Discussion paper. The Scottish Office, Edinburgh.

Scottish Office, Department of Health (1998b) Activities Underpinning Clinical Governance. In: Guidance - MEL on Clinical Governance. June 1998. URLhttp://www.show.scot.nhs.uk/dtc/index.ht m (7 January 1999)

Smith B.A. (1998) The problem drinker's lived experience of suffering: an exploration using hermeneutic phenomenology. Journal of Advanced Nursing 27 (1): 213-222.

Walsh D. (1996) Evidence-based practice: whose evidence and on what basis? British Journal of Midwifery. 4 (9): 454 - 457.

Walsh M and Ford P (1989) Nursing Rituals, Research and Rational Actions. Heinemann Nursing, Oxford.

Wiles R (1997) Empowering practice nurses in the follow-up of patients with established heart disease: lessons from patients' experiences. Journal of Advanced Nursing. 26: 729-735.

Vanora Hundley is a lecturer at the Centre for Advanced Studies in Nursing at the University of Aberdeen, and an Honorary Research Fellow in the Dugald Baird Centre for Research on Women's Health. 